\title{
Grants and opportunities
}

\section{Rapid Response Facility-call for applications}

The Rapid Response Facility (RRF) is a small grants programme jointly operated by the UNESCO World Heritage Centre, the UN Foundation and Fauna \& Flora International. It aims to provide rapid support to areas of high biodiversity value in times of crisis, primarily within UNESCO natural World Heritage sites. The RRF provides emergency funding of up to USD 30,000 to address severe and time sensitive threats to biodiversity. Funded projects have a maximum duration of 6 months. The Facility accepts applications year-round and prioritizes its resources to fund emergency conservation activities. Since its inception the RRF has reviewed and provided funding decisions to applicants within an average of 8 working days. Successful applicants need to demonstrate how the site in question is facing an urgent existing or impending threat to biodiversity and how rapid access to a small grant will contribute significantly to alleviating that threat.

Conservation emergencies tackled with RRF support have included: rapidly escalating habitat destruction because of illegal encroachment and road-building; rehabilitation of conservation infrastructure following armed conflict; intensified wildlife poaching; and unexpected and critical budget failures and natural disasters, such as the 2008 earthquake in China's Sichuan province. Beneficiaries eligible for grants include: statutory agencies responsible for site management (for example, national natural resource/ wildlife agencies, park managers); registered local, national or international NGOs; and the private sector (including local and multinational corporations). Grants are not made to individuals.

Applicants are encouraged to contact a member of the Secretariat via e-mail (rrf@fauna-flora.org) prior to submitting an application. The Secretariat is available to answer questions about organizational or site eligibility in advance of submitting a full application.

If your site and project fit RRF funding criteria, download an RRF application form from the RRF website (http://www.rapid-response.org, where further information, detailed eligibility criteria and guidelines are available). The completed application form should be submitted via e-mail to the RRF Secretariat at rrf@fauna-flora.org Successful applicants will be required to submit both financial and technical reports within 1 month of the end of their grant period. Applicants are invited to submit enquiries and applications in English, French or Spanish.

\section{The Rufford Small Grants for Nature Conservation}

The Rufford Small Grants for Nature Conservation are aimed at small conservation programmes and pilot projects that take place outside the developed world. Since the fund began in 1999 it has supported more than 1,500 projects in over 120 countries. There are five different Rufford Small Grants (RSG) beginning with a first RSG of up to GBP 6,000 . Once a successful first project has been completed recipients can then apply for a second RSG (also GBP 6,000 ) followed by a booster grant of up to GBP 12,000. For those who have successfully completed a booster grant there are two larger grants available, a Continuation Grant of up to GBP 25,000 and a Completion Grant of up to GBP 25,000 .

Individuals or small groups are invited to apply to Rufford Small Grants for Nature Conservation for projects that are primarily field-based and have a measurable and long-lasting conservation impact. Ideally, a Rufford Small Grant should make up the majority of the project's total budget and projects should be between 12 and 18 months in length, although as each application is assessed on its own merit project duration can be flexible.

Applications must be submitted online and can be made at any time throughout the year. It will normally take about 3 months for a decision to be reached. For further information and to apply visit http://www.ruffordsmallgrants.org/

Rufford Small Grants for Nature Conservation are particularly keen to encourage applications from the following countries, which have been under-represented in terms of applications in the past: Afghanistan, Algeria, Burundi, El Salvadore, Eritrea, Iraq, Jordan, North Korea, Lebanon, Libya, Mali, Mauritania, Niger, Paraguay, Suriname, Syria, Tonga, Tunisia, Turkmenistan and Western Sahara.

Please note projects not eligible for Rufford Small Grant funding are those based in the developed world and pure research projects with no direct conservation outcomes. The fund does not support conference or seminar attendance or participation in expeditions.

There is more information about criteria and eligibility for these grants on the Rufford website at http://www. ruffordsmallgrants.org/rsg/criteria 